\title{
Modelled lung deposition and retention of welding fume particles in occupational scenarios: a comparison to doses used in vitro
}

\author{
Sarah McCarrick ${ }^{1} \mathbb{D} \cdot$ Hanna L. Karlsson ${ }^{1} \cdot$ Ulrika Carlander $^{1}$
}

Received: 16 December 2021 / Accepted: 2 February 2022 / Published online: 21 February 2022

(c) The Author(s) 2022

\begin{abstract}
Translating particle dose from in vitro systems to relevant human exposure remains a major challenge for the use of in vitro studies in assessing occupational hazard and risk of particle exposure. This study aimed to model the lung deposition and retention of welding fume particles following occupational scenarios and subsequently compare the lung doses to those used in vitro. We reviewed published welding fume concentrations and size distributions to identify input values simulating reallife exposure scenarios in the multiple path particle dosimetry (MPPD) model. The majority of the particles were reported to be below $0.1 \mu \mathrm{m}$ and mass concentrations ranged between 0.05 and $45 \mathrm{mg} / \mathrm{m}^{3}$. Following 6-h exposure to $5 \mathrm{mg} / \mathrm{m}^{3}$ with a count median diameter of $50 \mathrm{~nm}$, the tracheobronchial lung dose $\left(0.89 \mu \mathrm{g} / \mathrm{cm}^{2}\right)$ was found to exceed the in vitro cytotoxic cell dose $\left(0.125 \mu \mathrm{g} / \mathrm{cm}^{2}\right)$ previously assessed by us in human bronchial epithelial cells (HBEC-3kt). However, the tracheobronchial retention decreased rapidly when no exposure occurred, in contrast to the alveolar retention which builds-up over time and exceeded the in vitro cytotoxic cell dose after 1.5 working week. After 1 year, the tracheobronchial and alveolar retention was estimated to be 1.15 and $2.85 \mu \mathrm{g} / \mathrm{cm}^{2}$, respectively. Exposure to low-end aerosol concentrations resulted in alveolar retention comparable to cytotoxic in vitro dose in HBEC-3kt after 15-20 years of welding. This study demonstrates the potential of combining real-life exposure data with particle deposition modelling to improve the understanding of in vitro concentrations in the context of human occupational exposure.
\end{abstract}

Keywords Welding $\cdot$ Exposure $\cdot$ Particle deposition $\cdot$ Lung dose $\cdot$ In vitro

\section{Introduction}

Welding fumes are created as a by-product of the welding process and contain toxic metals including chromium, nickel and manganese that are of concern for occupational health. Approximately 10 million people are estimated to somehow be exposed to welding fumes in their occupational setting (IARC 2017), where the metal-containing fumes have been linked to several health outcomes including bronchitis, respiratory irritation, and inflammation (Antonini 2003; Zeidler-Erdely et al. 2012; Riccelli et al. 2020). Welding fumes are further established to be carcinogenic to humans by the International Agency for Research on Cancer (IARC 2017). Yet, no common welding specific occupational exposure limit (OEL) has been established within the European

Sarah McCarrick

sarah.mccarrick@ki.se

1 Institute of Environmental Medicine, Karolinska Institutet, 17177 Stockholm, Sweden union (EU), instead 8-h OEL for (inorganic) dust or separate OELs for specific metals such as manganese and hexavalent chromium are often used (Sjögren et al. 2021). Recently, an evaluation of OEL for welding fume in the EU has been initiated by the European chemicals agency.

Using in vitro systems, we and others have demonstrated toxic effects in cultured cells exposed to welding fume particles, including cytotoxicity, oxidative stress, DNA damage and inflammatory effects (Antonini et al. 1999, 2005; McNeilly et al. 2004; Leonard et al. 2010; Shoeb et al. 2017; McCarrick et al. 2019, 2021; Hedberg et al. 2021). In vitro toxicity test methods offer the potential for efficient, economical and ethical hazard testing as an alternative to animal testing. However, extrapolating human health risk from chemical exposure based on in vitro data is a challenging task. One important aspect lies in the in vitro dose selection, where scientific justification and consideration for real world exposure is crucial to provide useful data for toxicological hazard and risk assessment (Oberdörster and Kuhlbusch 2018; Romeo et al. 2020). 
Aerosol exposure concentration is frequently considered as an acceptable measure for lung dose in experimental studies, risk assessments and in the derivation of regulatory limit values. Nevertheless, this may be deceiving since the exposure has been argued to be a poor predictor of delivered dose in the lung (Oller and Oberdörster 2016). Lung dose is dependent on several factors including aerosol concentration, respiratory parameters and particle characteristics affecting the mobility and behavior of the particles (Oberdörster et al. 2005; Hofmann 2020). As argueed by Schmid and Cassee (2017), the concept of delivered dose is of principal significance for any type of particle exposure and the relevant measure for toxicological dose-response analysis for human risk assessment. Therefore, data on the deposition and clearance of particles in the human respiratory system are key parameters to assess the association between human exposure and in vitro dose levels.

As emphasized in the review by Riccelli et al. (2020), the quantification of welding particle deposition and its clearance are essential for evaluating their health risks. In contrast to readily measured exposure concentrations, delivered dose is difficult to quantify. Efforts have been made to determine the fate of welding fume particles in vivo, including assessments of lung deposition, clearance and extrapulmonary distribution (Kalliomäki et al. 1978; Antonini et al. 2010, 2011; Falcone et al. 2017; Stanislawska et al. 2020). Nonetheless, experimental determination of particle deposition is limited to primarily total lung deposition with regional deposition of less accuracy. To refine health risk assessment, dosimetry models can serve as an alternative to provide more detailed information on local deposition patterns in the human lung. These models can also aid in the translational framework needed to relate nominal concentrations inducing biological response to a relevant human exposure level, i.e., in vitro to in vivo extrapolation (IVIVE) (Anjilvel and Asgharian 1995; Miller et al. 2016; Romeo et al. 2020). A widely accepted model providing detailed dosimetry data is the multiple-path particle dosimetry (MPPD) model. By adopting the MPPD model, the total, regional and lobar deposition fraction per airway can be attained and the influence of particle specific aerosol characteristics and respiratory parameters can be assessed (Anjilvel and Asgharian 1995; Miller et al. 2016). The estimated regional lung doses can further be used to correlate in vivo particle exposure levels to in vitro dose levels, as previously done by Gangwal et al. (2011) among others.

The aim of this study was to investigate the deposition of welding fume particles in the lung following real-life occupational exposure scenarios and to explore how this can be related to doses used in vitro. To find relevant exposure data, a comprehensive literature search of available studies was performed. We reviewed the articles and selected relevant articles based on the following criteria: (1) occupational exposure data for welding fumes measured within industrial workplaces or laboratories; and (2) size distribution of the particles with at least 4 size fractions. Secondly, the multiple-path particle dosimetry (MPPD) model was used to run hypothetical exposure scenarios and investigate the role of particle size distribution, particle density, exposure concentrations, body position and breathing patterns for deposition and retention in the tracheobronchial and alveolar region of the lung, respectively. Finally, the modelled doses were linked to doses and findings from our own in vitro studies. The quantification of particle deposition and clearance is essential for finding links between real-life exposure to welding fume and toxic effects studied in vitro, and thus has implications in the risk assessment of workers exposed to welding fumes.

\section{Method}

\section{Literature search}

The search was conducted during June 2021 in Web of Science. The search terms included the following: weld* AND fume* AND exposure*. The articles dating from 2010 and onwards were evaluated with regard to relevance for our study.

In a first screening, we included studies meeting the following inclusion criteria regarding exposure assessment: publications with original occupational quantitative measurements of solely welding fumes (not mixed work), measurement of total fume and thus not only single metal constituents and aerosol concentrations reported in number or mass. Only peer-reviewed publications written in English were included. We excluded reviews and studies based on pre-defined simulations, exposures based on biomarkers or questionaries and other non-relevant topics (such as in vivo and in vitro studies) on the basis of abstract and/or full text. To be able to generate results useful for the MPPD modelling, publications reporting welding concentrations in other metrics than mass or number (e.g., surface area) were not considered further.

After preliminary screening, studies considered relevant were assessed for eligibility for MPPD modelling regarding reported size distribution with the following inclusion criteria: original quantitative size distribution measurements with at least 4 size fractions. Studies with no size distribution data or size distributions with less than 4 size fractions (e.g., inhalable and respirable fraction) or based on TEM-imaging were further excluded.

\section{Data extraction and reporting}

From all the articles that met the inclusion criteria, information of interest was extracted and summarized. General 
information was collected on population investigated, location, welding method and base material. Data on exposure concentrations and size distributions were gathered from the publications without processing to the extent as possible, unless otherwise specified. If certain information/data were not available in the publication, these were stated as not reported (NR), unless specifically stated.

The method used to determine size distribution including metric and size range of the instrument were noted. To ensure consistency in data extraction, the following rules were specified: if geometric mean aerodynamic diameter (GMAD) or count median diameter (CMD) with GSD were reported in the studies these were extracted without processing. If only a graph of the size distribution curve was available, a GMD was calculated by collecting datapoints from the graph using WebPlotDigitizer (https://automeris.io/ WebPlotDigitizer/2. If size was reported in mass frequency distribution in the different size fractions, this was reported without processing. If size distribution was stated as mass/ number in different size fractions, these were converted to $\%$ of total mass/number based on total particulate matter (PM) reported in the study, or if not available the sum of all fractions reported. All values calculated by us are marked with *.

Data on aerosol concentration measurements including the instrument used for quantification, the sampling matrix, location of measurement and duration of measurement was collected. Concentration in mass $\left(\mathrm{mg} / \mathrm{m}^{3}\right.$ ) or number (particles $/ \mathrm{cm}^{3}$ ) were extracted in the format stated in the publication including mean (geometric or arithmetic), median, range or single measurement with associated variance. If two concentration values were given, they were both included whereas more than two means or medians were given as a range.

\section{MPPD modelling}

The MPPD dosimetry model v3.04 (ARA) was used. MPPD is a mechanistic model that calculates deposition and clearance based on user-provided input on airway morphometry, particle properties, exposure scenario and clearance rates (Anjilvel and Asgharian 1995; Miller et al. 2016). To determine the deposition of welding fume particles in the lung, we initially selected a baseline set of MPPD inputs based on a combination of data on physiological parameters from the ICRP report (ICRP 1994) and welding particle specific data based on the results of our literature compilation. The MPPD model offers two sets of exposure conditions: constant or variable. Our simulations were performed using constant exposure conditions with or without clearance. We further varied selected parameters (size, exposure concentration, particle density, workload, body position) systematically to evaluate the key determinants for deposition of welding fume particles in the lung.

The results were visualized using GraphPad Prism 8.0.1 (GraphPad Inc., La Jolla, CA).

\section{Baseline input values}

The airway morphometry selected in the MPPD model was the Yeh-Schum 5-lobe lung model based on data by Yeh and Schum (1980) with variable path lengths among the five lobes but symmetric branching within each lobe to better reproduce the asymmetry of the airway branching pattern.

The particles were assumed to be spherical (aspect ratio of 1). The baseline density was set to $7.9 \mathrm{~g} / \mathrm{cm}^{3}$, corresponding to the density of iron $(\mathrm{Fe})$. Baseline size distribution was based on the results of the literature compilation. Function for adjustment of particle inhalability was used to correct for particles ability to reach and enter the upper respiratory tract (Asgharian et al. 2018).

The baseline breathing pattern was selected to simulate light exercise, referred to as medium workload, corresponding to oronasal-mouth breather with 20 breaths per minute and a tidal volume of $1250 \mathrm{~mL}$. Body orientation was set to upright. The baseline exposure concentrations was set to the general OEL used in the regulation of welding fumes corresponding to $5 \mathrm{mg} / \mathrm{m}^{3}$ according to IARC (2017). This is equivalent to the OEL for inorganic inhalable dust used for welding fumes in Sweden (Swedish Work Environment Authority 2018). Default clearance values were selected in the MPPD model.

\section{MPPD simulations}

To investigate the influence of size distribution on deposition fractions, the MPPD model was run for deposition only (no clearance). A wide range of size distributions were selected from the results of the literature compilation to compare to the baseline (also selected from literature).

To study the welding fume particle retention (deposition and clearance), we simulated 1 week of exposure, assuming five working days with $6 \mathrm{~h}$ full exposure. This is in line with IARC, reporting the median duration of exposure to be $40 \mathrm{~h} /$ week for welders with $70 \%$ exposed full-time (IARC 2017). The MPPD calculations were performed, in addition to the baseline values, with a variation in concentration, size distribution, density $\left(1 / 4 \mathrm{~g} / \mathrm{cm}^{3}\right)$, work burden (light and heavy corresponding to $12 / 26$ breaths per minute and $625 / 1600$ tidal volume, respectively) and body position (on back, leaning forward). A wide range of size distributions was selected based on the results of the literature review. Further, the lowest and the highest exposure concentration reported in the literature review were used to simulate the far ends of the exposure range in relation to the OEL. To be 
able to use the OEL as a baseline, we decided to only use the range of concentrations reported in mass. However, we recognize that other lung deposition metrics (such as particle number and particle surface area) are important for understanding the health risks (Oberdörster et al. 2005; Schmid and Stoeger 2016).

Finally, a 1-year simulation (52 weeks, 5 working days/ week with $6 \mathrm{~h} /$ day of exposure) was run for the baseline input values as well as a 45 -year simulation (2340 weeks, 5 working days/week with $6 \mathrm{~h} /$ day of exposure) for the low end-exposure level with remaining baseline values.

\section{Calculations of retention per surface area}

The results on tracheobronchial and alveolar retention that were given by the MPPD model were further converted to retention per surface area by dividing the retention by total surface area of the different regions. The total tracheobronchial $\left(3220 \mathrm{~cm}^{2}\right)$ and alveolar surface area $\left(786,000 \mathrm{~cm}^{2}\right)$ was obtained from the MPPD model by summing the tracheobronchial surface area for generation $1-17$ or the pulmonary surface area for generation 16-25, respectively. Together, the total area of the tracheobronchial and alveolar region corresponds to approximately $79 \mathrm{~m}^{2}$.

\section{Comparison of MPPD calculated lung doses to in vitro}

The surface area lung retention reached following the different exposure scenarios was directly compared to in vitro doses previously used by us to assess toxicity of welding fumes generated from stainless steel flux cored arc welding in human bronchial epithelial cells (HBEC-3kt) under submerged conditions (McCarrick et al. 2021). The in vitro doses were given as $\mu \mathrm{g} / \mathrm{mL}$ but were converted to $\mu \mathrm{g} / \mathrm{cm}^{2}$ by assuming $100 \mu \mathrm{L}$ exposure medium and a growth area of $0.32 \mathrm{~cm}^{2}$ in a 96 -well plate. The nominal dose was based on full sedimentation and bioavailability, whilst the cellular dose assumed 5\% uptake based on uptake measurements in McCarrick et al. (2021). The half maximal effective concentration (EC50) of the most cytotoxic welding fume tested, i.e., the dose eliciting a reduction of 50\% cell viability, was included to represent an in vitro dose inducing a response. However, since this was the most toxic welding fume tested, it can be considered as a type of worst-case exposure.

\section{Results}

\section{Literature search}

The literature search generated 493 articles, out of which 79 were identified with a suitable exposure assessment of welding fume particles (414 excluded). Out of these, 15 articles met the established criteria of reporting size distribution with at least 4 size fractions to be used to generate input values for the MPPD modelling (64 excluded). The literature search flow is illustrated in Fig. 1.

The selected studies from the literature search provide data in a variety of welding occupations as well as methods and materials used in the welding process, see Table 1 or for more details Table S1 and S2. The studies identified generally fell into two broad categories: experimental investigations and field studies. The experimental studies involved somewhat controlled settings (worker, location, time frame of welding etc.) where the field studies were more uncontrolled and may therefore to a larger extent include the presence of confounders (such as co-exposures from surrounding operations), however this can be argued to provide a more real-world exposure. The studies differed in measurement approaches including both gravimetric and real-time measurements as well as both personal and static/stationary measurements. The measurement instruments used for measuring concentrations and size distribution in the various studies have different operation principles and measurement ranges. Measurements were further reported in breathing zone and a variety of other distances from the welding source. Based on these factors, the concentrations and size distributions reported in the studies may not be fully comparable. Even so, the results presented here may be considered representative for general levels and size distributions of welding fume particles in occupational settings.

\section{Reported size distribution of welding fume particles}

The collected size distributions can be found in Table 1, or for more details in Table S1. Particle size distribution is usually defined in two categories; either based on geometric diameter or aerodynamic diameter. A geometric mean diameter (GMD) was reported or calculated in six studies, ranging between $0.01-0.10 \mu \mathrm{m}$ out of which only one reported a multimodal distribution (Miettinen et al. 2016). Count median diameters (CMD) was reported in Lai et al. (2016) with a bimodal distribution with a $1 \mathrm{st}$ peak at $0.014-0.015 \mu \mathrm{m}$ and a $2 \mathrm{nd}$ peak at $0.13-0.14 \mu \mathrm{m}$. Mass median aerodynamic diameter (MMAD) was further reported in four studies demonstrating a bimodal distribution with a 1st peak between $0.3-1.5$ and 2 nd peak at 1.4-9.8 $\mu \mathrm{m}$. Debia et al. (2014) reported the main mode to range between $0.030-0.098 \mu \mathrm{m}$ and $0.050-0.21 \mu \mathrm{m}$ for different welding methods measured during the whole welding period or only during welding activities, respectively. Ham et al. (2012) reported the size distributions in a 3D-graph and therefore we could not process the data further.

Several studies reported size distribution in fractions, of which the smallest size fraction as well as size fractions 


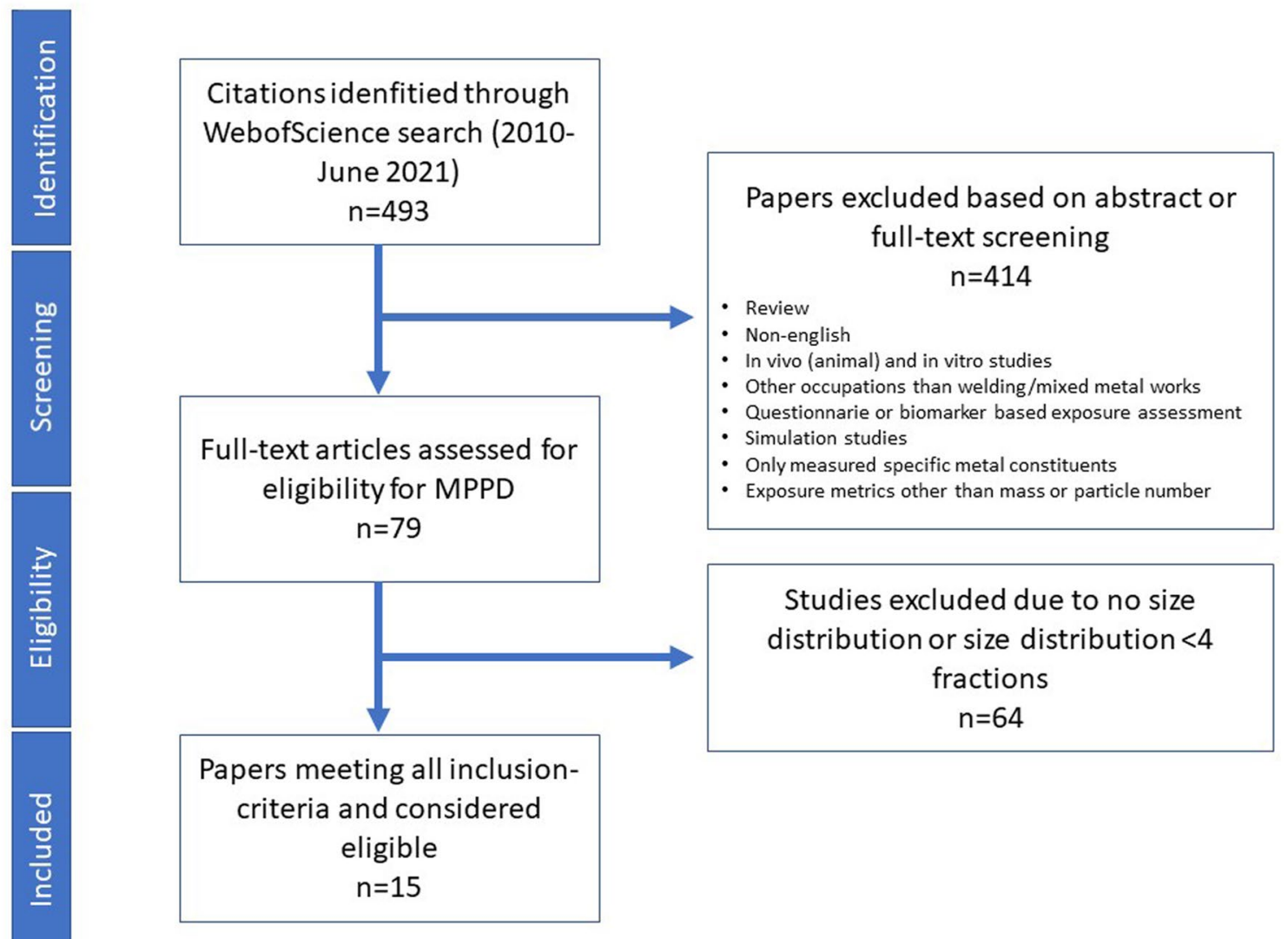

Fig. 1 Literature search flow

closest to PM1, PM2.5 and PM10 are reported in Table 1. More details on the size fractional distribution can be found in Table S1. Based on particle number, the majority of the particles were reported to be below $0.1 \mu \mathrm{m}$ in Debia et al. (2014) (48-88\%), Graczyk et al. (2016) (92\%), Ham et al. (2012) (64-68\%) and Lehnert et al. (2012) (54\%). Lai et al. (2016) and Young et al. (2013) reported 9 and 14\% to be below $0.1 \mu \mathrm{m}$, respectively, based on mass. However, the mass-based majority of the particles were reported to be below $0.25 \mu \mathrm{m}$ in Hedmer et al. (2014) (53\%) and Lai et al. (2016) (84\%).

The size-limit of the used instruments has a great impact on the final results of the size distributions and is an essential factor when comparing different studies, see details on the size-ranges of the various instruments in Table S1. The low end of the measurement range for the instruments varied from 0.0056 to $0.52 \mu \mathrm{m}$. The particles of interest in this study are primarily those within the nano-range $(<0.1 \mu \mathrm{m})$, therefore the studies investigating size distribution with a minimum size limit larger than $100 \mathrm{~nm}$, including Kirichenko et al. (2019), Lin et al. (2015), Sajedifar et al. (2018), Yang et al. (2018), Zugasti et al. (2012), were not considered as central in the decision of the input values for the MPPD modelling.

\section{Reported exposure concentrations of welding fume particles}

The reported exposure concentrations of welding fume particles from the 15 studies identified in the literature search are found in Table 1, for more details about methods and measurement position, see Table S2. A mixture of gravimetric and real-time measurements was identified where a majority of the studies measured total PM, while some performed only size-selective sampling including PM10, PM4, PM2.5 or ultrafine particles (for details see Table S2). Total particulate matter, inhalable or the largest reported size fraction concentrations are reported in Table 1, more details on other fractional concentrations can be found in Table $\mathrm{S} 2$.

A total of nine studies have reported mass concentrations of welding fumes specifically measured in the breathing zone of welders (see Table S2), ranging from 0.049 (PM2.5) to 45 (total PM) $\mathrm{mg} / \mathrm{m}^{3}$. The majority of the breathing zone measurements were found in field 


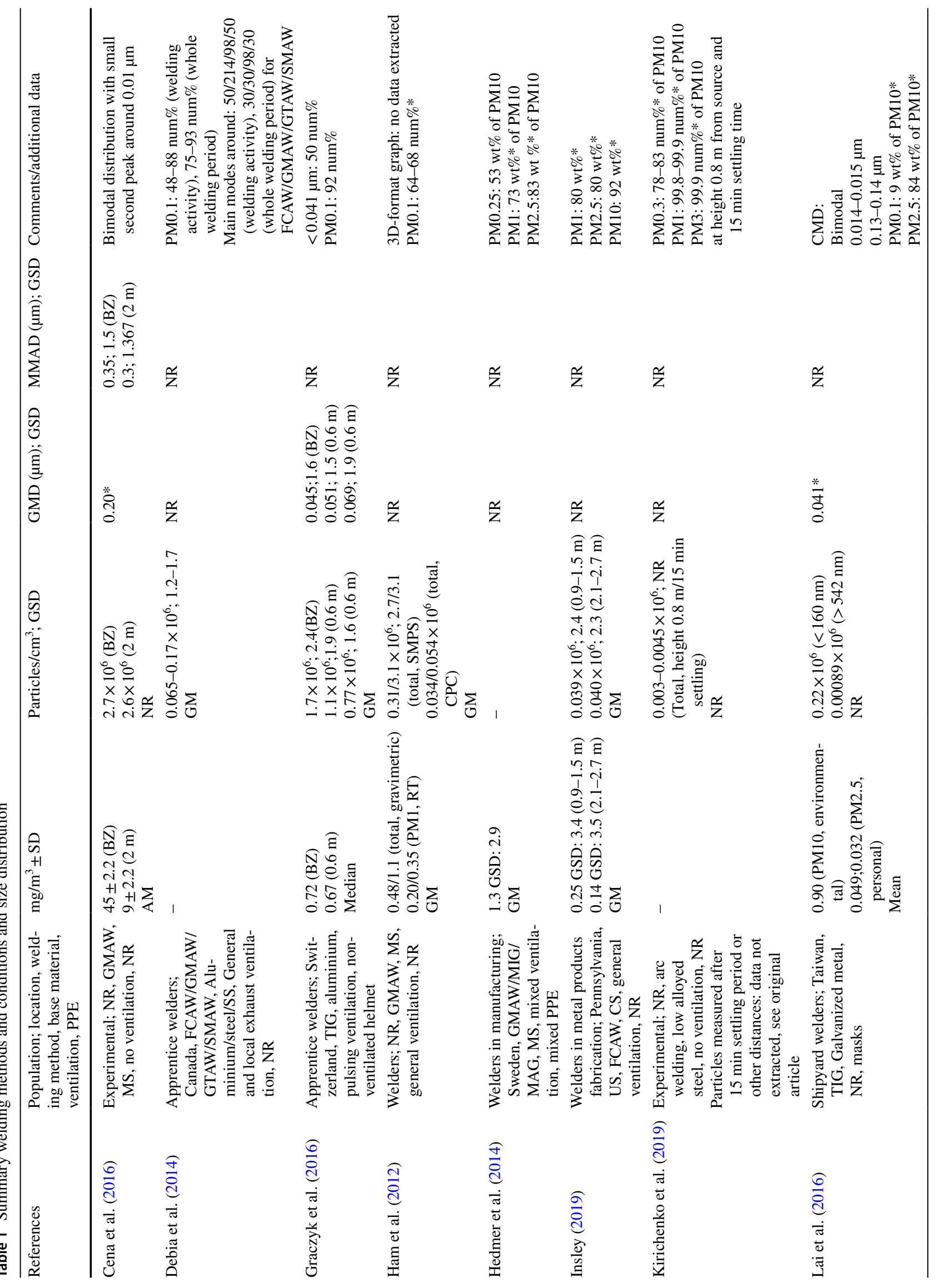




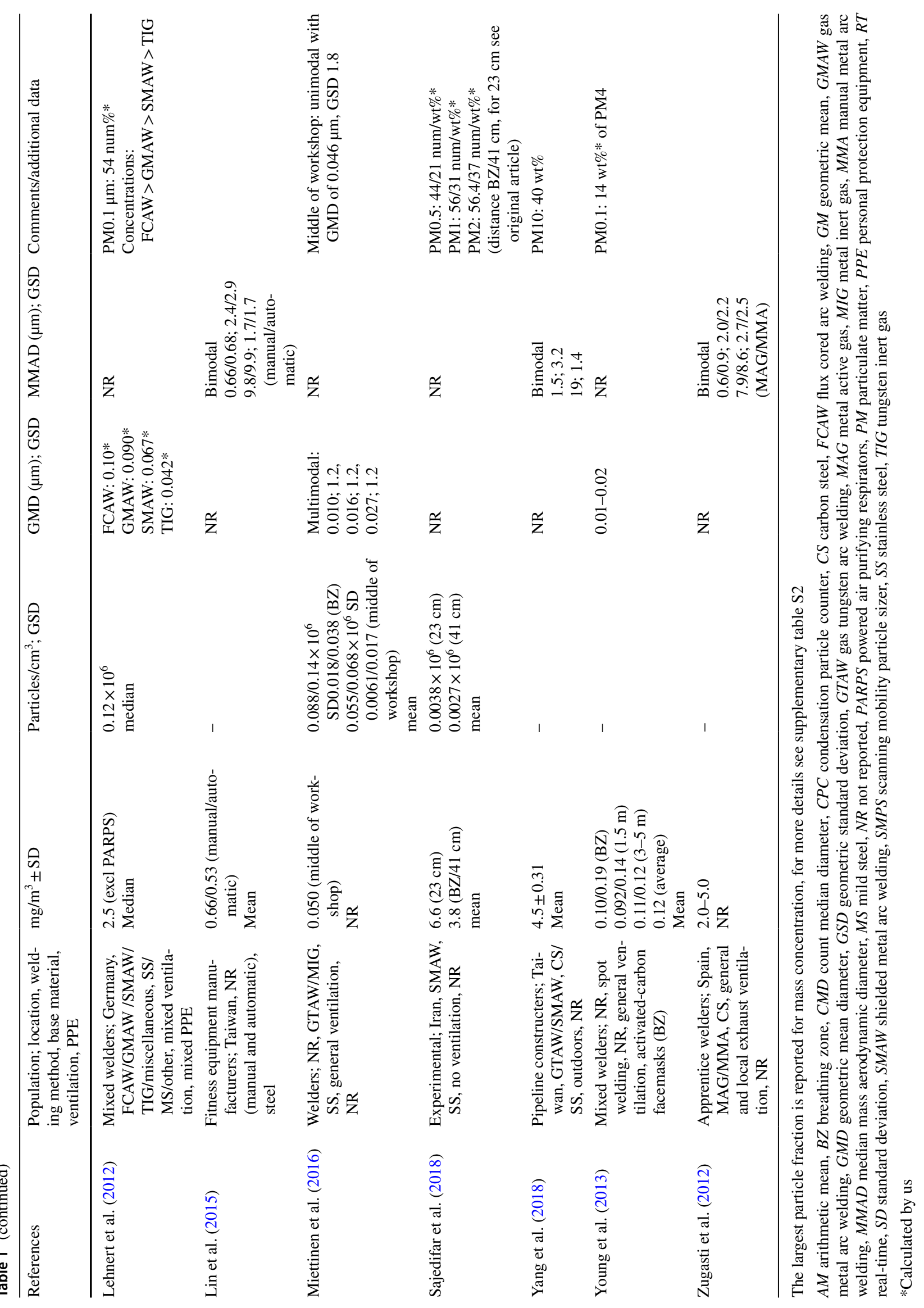


studies reporting levels between 0.049 and $4.45 \mathrm{mg} / \mathrm{m}^{3}$, while the experimental reported $3.8-45 \mathrm{mg} / \mathrm{m}^{3}$. Measurements outside of the breathing zone, at various distances, ranged from 0.05 to $9 \mathrm{mg} / \mathrm{m}^{3}$. Gravimetrically measured mass concentrations ranged between 0.05 and $45 \mathrm{mg} /$ $\mathrm{m}^{3}$, while real-time measurements ranged between 0.049 and $6.6 \mathrm{mg} / \mathrm{m}^{3}$. The overall concentrations of the lowest range were reported in the breathing zone by Lai et al. (2016) $\left(0.049 \mathrm{mg} / \mathrm{m}^{3}, \mathrm{PM} 2.5\right)$ as well as in the middle of the workshop by Miettinen et al. (2016) $\left(0.05 \mathrm{mg} / \mathrm{m}^{3}\right.$, total PM). The overall highest concentration was reported by Cena et al. (2016), measuring $45 \mathrm{mg} / \mathrm{m}^{3}$ at welders breathing zone. This was measured under experimental conditions inside a walk-in chamber under calm-air conditions representing welding in industrial facilities with no or poor ventilation or in restricted work environments with minimal air movements.

Number concentrations in the breathing zone ranged between 0.0027 and $2.7 \times 10^{6}$ particles $/ \mathrm{cm}^{3}$. The highest number concentration in breathing zone of $2.7 \times 10^{6}$ particles $/ \mathrm{cm}^{3}$ was reported by Cena et al. (2016) under conditions without ventilation. Measurements outside of the breathing zone at various distances from the source ranged between 0.00089 and $3.1 \times 10^{6}$ particles $/ \mathrm{cm}^{3}$. The overall highest number concentration was reported by Ham et al. (2012), reporting $3.1 \times 10^{6}$ particles $/ \mathrm{cm}^{3}$ in welding workplace with general ventilation through doors and windows. The overall lowest concentration was reported by Lai et al. (2016) in a semi-open welding area, however this only included particles above the size of $542 \mathrm{~nm}$.

Due to different experimental designs and measurement approaches, it is generally difficult to draw any conclusions on concentration in breathing zone versus non-breathing zone, or gravimetric vs real-time measurements. Although some studies measured the concentration depending on specific welding parameters including welding method and base metal, this was outside the scope of this article and thus not distinguished in the tables.

\section{Justification for MPPD input values}

Particle size distribution was reported in different formats including GMD and MMAD, of which a baseline size distribution value was selected based on the reported GMDs. Several studies reported a GMD of 0.041-0.069 $\mu \mathrm{m}$, even though both larger and smaller GMDs were also reported (Table 1). The GMDs reported in the literature review are considered equal to count median diameter (CMD) if assuming log-normal distribution. Based on the reported size distribution, we selected a baseline particle CMD of $0.05 \mu \mathrm{m}$. Further, we assumed a single mode size distribution with a size geometric standard deviation (GSD) of 1.2. The complete baseline MPPD input values can be found in Table 2 .

To determine the influence of size distribution on the deposition, the size ranges of CMD was selected between 0.01 and $1 \mu \mathrm{m}$ with a GSD of 1.2 or 2 , to cover all sizes reported in Table 1. To consider the reported aerodynamic diameters, MMAD between 0.35 and $1.4 \mu \mathrm{m}$ with a GSD of 1.2 or 2 were also included.

The maximum and minimum reported exposure concentration was extracted directly from Table 1: 0.05 and $45 \mathrm{mg} /$ $\mathrm{m}^{3}$.

\section{The deposition fraction depends on particle size, but distribution over generations is altered when normalizing for lung surface area}

The impact of particle size distribution on the regional deposition fraction during a single breath was determined using a variation of size distributions of CMD ranging from 0.01 to $1 \mu \mathrm{m}$ as compared to baseline input values (CMD $0.05 \mu \mathrm{m}$ ). The results expressed in deposition fraction over generation number are visualized in Fig. 2A. Overall, the smallest size of CMD $0.01 \mu \mathrm{m}$ resulted in the largest total deposition. In the tracheobronchial region, CMD $0.01 \mu \mathrm{m}$ was deposited to the largest extent, followed by CMD $0.1 \mu \mathrm{m}$. The remaining sizes were found to deposit in the tracheobronchial region to a similar extent. In the alveolar region, CMD of $0.01 \mu \mathrm{m}$ resulted in the largest deposition, followed by 0.05 and $1 \mu \mathrm{m}$.

Table 2 MPPD input values—baseline

\begin{tabular}{|c|c|}
\hline MPPD categories & Baseline input settings \\
\hline Airway morphometry & human species; Yeh-Schum 5-lobe lung model; FRC $=3300 \mathrm{~mL}$; URT volume $=50 \mathrm{~mL}$ \\
\hline Particle properties & $\begin{array}{l}\text { density }=7.9 \mathrm{~g} / \mathrm{cm}^{3} ; \text { aspect ratio }=1 ; \text { count median diameter }=0.05 \mu \mathrm{m} ; \text { inhalability adjustment checked; GSD } \\
\quad(\text { diam. })=1.2\end{array}$ \\
\hline $\begin{array}{l}\text { Exposure scenario: } \\
\text { constant exposure }\end{array}$ & $\begin{array}{l}\text { Acceleration of gravity }=981 \mathrm{~cm} / \mathrm{s}^{2} ; \text { body orientation }=\text { upright; aerosol concentration }=5 \mathrm{mg} / \mathrm{m}^{3} ; \text { breathing fre- } \\
\text { quency }=20 / \mathrm{min} ; \text { tidal volume }=1250 \mathrm{~mL} \text {; inspiratory fraction }=0.5 ; \text { breathing scenario }=\text { oronasal-mouth breather }\end{array}$ \\
\hline & Number of hours per day $=6$; number of days per week $=5$; number of weeks $=1 / 45 / 2340 ;$ max. post-exposure days $=0$ \\
\hline Clearance settings & $\begin{array}{l}\text { tracheal mucous velocity }=5.5 \mathrm{~mm} / \mathrm{min} \text {; fast human clearance rate }=0.02 / \text { days, medium human clearance rate }=0.001 / \\
\text { days; slow human clearance rate }=0.0001 / \text { day; lymph node human clearance rate }=0.00002 / \text { day }\end{array}$ \\
\hline
\end{tabular}

$F R C$ functional residual capacity, $U R T$ upper respiratory tract 


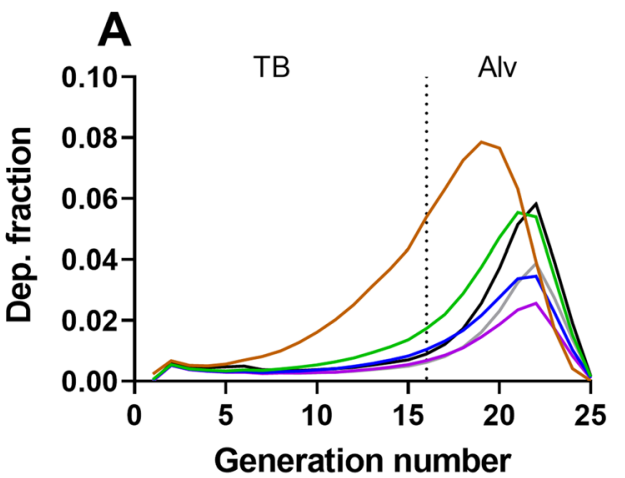

Fig. 2 Deposition fraction per generation number depending on particle size distribution. Results are expressed as deposition fraction over generation number (A) or deposition fraction per surface area (SA) over generation number $(\mathbf{B})$. Baseline input values were used includ-

CMD $0.2 \mu \mathrm{m}$ was deposited to the least extent in the alveolar region.

Figure 2B shows the deposition fraction normalized to regional lung surface area (deposition fraction $/ \mathrm{cm}^{2}$ ) over generation number. As a result of the varying surface areas of the different region of the lung, the deposition distribution over generation number is shifted, as compared to Fig. 2A. The results demonstrate an overall higher deposition fraction per surface area in the tracheobronchial region, particularly in the first generations, as compared to the alveolar region.

Identical simulations were performed with MMAD as size distribution input (MMAD 0.35-1.4 $\mu \mathrm{m}$, GSD 1.2), Figure S1B. The results on deposition fraction demonstrate the smallest MMAD of $0.35 \mu \mathrm{m}$ to result in the highest total tracheobronchial and alveolar deposition. A size distribution with a MMAD of $0.7 \mu \mathrm{m}$ were found to deposit the least in the alveolar region but comparable to MMAD $1.4 \mu \mathrm{m}$ in the tracheobronchial region. When normalizing for surface area, similar to what was observed for GMD, the distribution was shifted to result in overall higher deposition in the upper generation numbers. The same simulations (CMD 0.01-1 $\mu \mathrm{m} / \mathrm{MMAD} 0.35-1.4 \mu \mathrm{m})$ were performed with a GSD of 2 (Figure S1A, C), but no substantial effect was seen on the results.

\section{Lung retention depends largely on particle size, concentration, and workload}

The regional lung retention (deposition and clearance) of welding fume particles was determined following a simulation of 1 week ( 5 days exposure, $6 \mathrm{~h} /$ day followed by 2 days of no exposure) for baseline input values as well as a variation of size distribution, exposure concentration, workload (Fig. 3), density and body position (Figure S2). In agreement with Fig. 2, the deposition in the tracheobronchial region is generally larger compared to the alveolar region but the

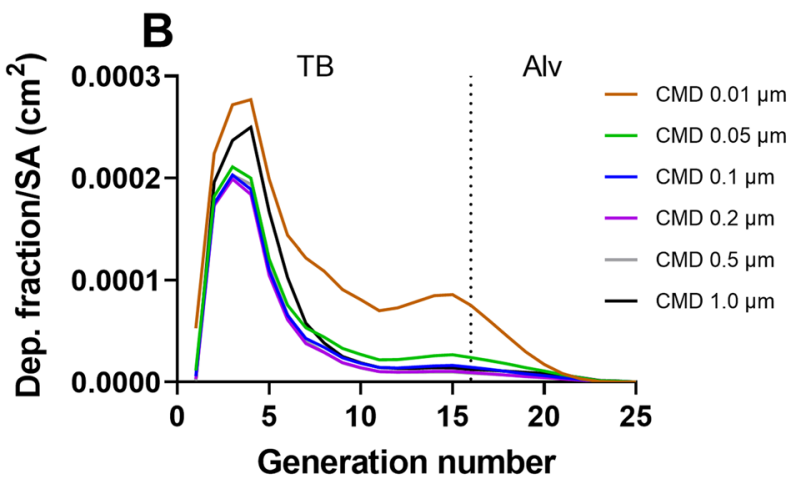

ing the occupational exposure limit concentration of $5 \mathrm{mg} / \mathrm{m}^{3}$ and moderate workload. The size distributions were varied from CMD $0.01-1 \mu \mathrm{m}$ with a of GSD 1.2

results demonstrate that the clearance mechanisms in the tracheobronchial region are more effective resulting in a rapid decrease in retention following time of non-exposure. In contrast, the retention of the alveolar region, which has much slower clearance mechanisms, is instead slowly built up over time. At the end of the work shift of day 1 or day 5 , with baseline values, the tracheobronchial retention corresponded to 0.89 and $1.15 \mu \mathrm{g} / \mathrm{cm}^{2}$ with an alveolar retention of 0.017 and $0.085 \mu \mathrm{g} / \mathrm{cm}^{2}$, respectively. At the end of the 1-week simulation, including 2 days without exposure and only clearance, the retention corresponded to 0.102 and $0.083 \mu \mathrm{g} / \mathrm{cm}^{2}$ in the tracheobronchial and alveolar region, respectively. The following results reflect the retention at the end of 1 week.

When altering the size distribution of the welding fume particles, the tracheobronchial and alveolar retention was increased 1.4-fold by CMD $0.01 \mu \mathrm{m}$ compared to CMD $0.05 \mu \mathrm{m}$ (baseline). In contrast, a CMD of 1 and $0.2 \mu \mathrm{m}$ resulted in a decrease of 1.1- or 2.3-fold, respectively.

The alveolar and tracheobronchial retention was found to change linearly as the external exposure concentration was altered. The maximum concentration of $45 \mathrm{mg} / \mathrm{m}^{3}$ resulted in a tracheobronchial and alveolar retention of 0.92 and $0.75 \mu \mathrm{g} / \mathrm{cm}^{2}$, corresponding to a ninefold increase compared to baseline concentration of $5 \mathrm{mg} / \mathrm{m}^{3}$. The minimum concentration of $0.05 \mathrm{mg} / \mathrm{m}^{3}$ resulted in a retention of 0.001 and $0.0008 \mu \mathrm{g} / \mathrm{cm}^{2}$ in the tracheobronchial and alveolar region, respectively, corresponding to more than a 100 -fold decrease from the baseline value.

An increase in workload from medium (baseline) to high resulted in a 1.9- and 1.8-fold increase in the retention in the tracheobronchial and alveolar region, respectively. The retention following low workload resulted in 0.027 and $0.022 \mu \mathrm{g} / \mathrm{cm}^{2}$ in the tracheobronchial and alveolar region, respectively, corresponding to an approximately fourfold decrease compared to baseline retention. 
Fig. 3 MPPD model results of tracheobronchial and alveolar retention per surface area versus time (h) during 1-week simulation assuming $6 \mathrm{~h}$ of exposure the first 5 days, followed by 2 days of only clearance. Baseline input values are marked in green and include a CMD of $0.05 \mu \mathrm{m}$ (GSD 1.2), the occupational exposure limit concentration of $5 \mathrm{mg} / \mathrm{m}^{3}$ and a moderate workload. The influence of a variation of $\mathbf{A}$ size distribution (GSD 1.2), B concentration and C workload (breathing pattern) were further explored. Final tracheobronchial and alveolar retention after 1 week (incl. weekend) for all simulations are shown in $\mathbf{D}$. The in vitro EC50 included in D represents a responsive cell dose found to elicit a reduction of $50 \%$ cell viability in human bronchial epithelial cells following 24-h exposure
Tracheobronchial retention

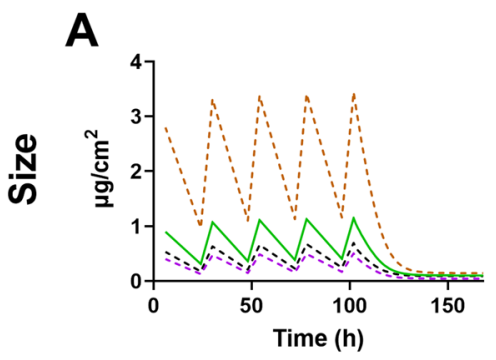

B

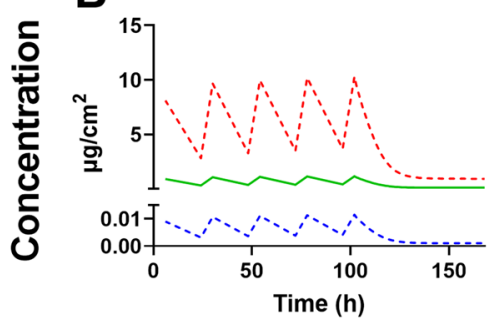

C

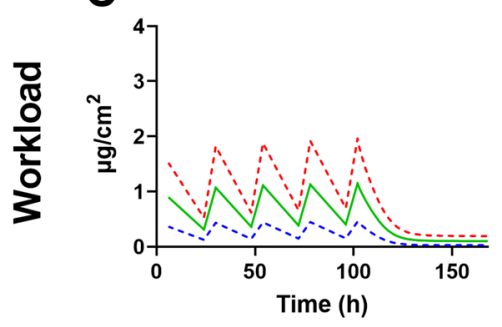

Alveolar retention
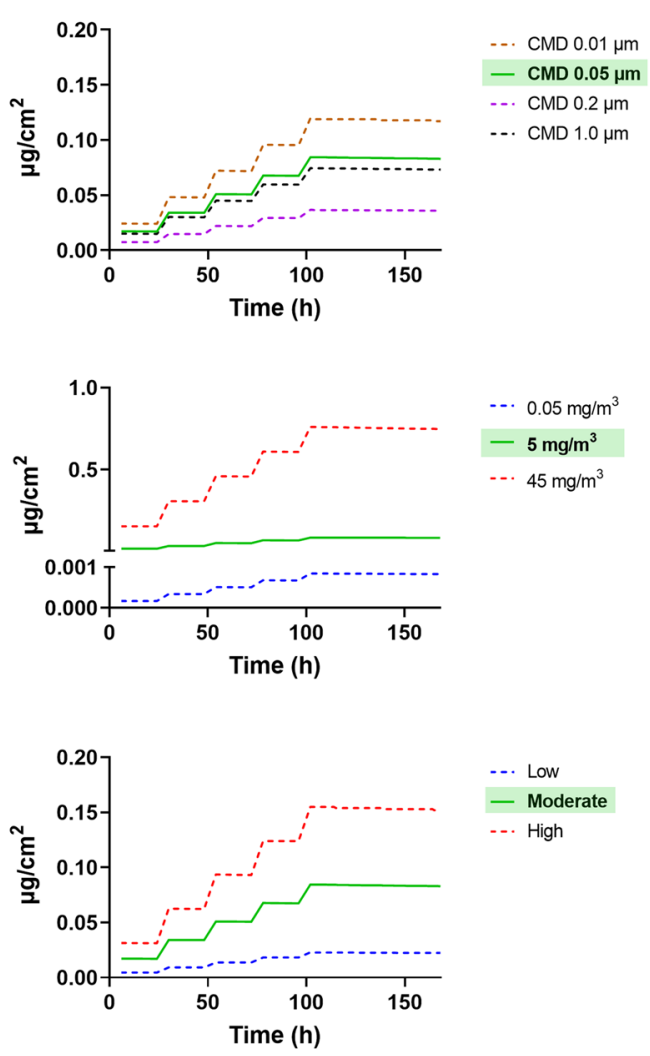

D

Final retention (168 h)

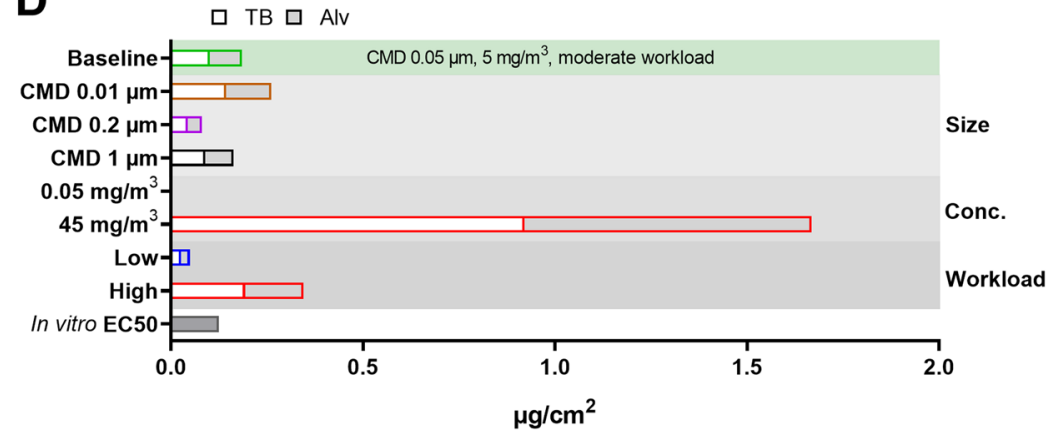

As visualized in Fig. 3D, our results demonstrate that aerosol concentration is the most important input parameter followed by workload and size distribution. In the 1-week simulation varying density and body position, no effect on the retention was observed (Figure S2).

\section{Alveolar retention is larger than tracheobronchial retention following chronic exposure}

The alveolar and tracheobronchial retention during 1-year simulation using the baseline input values is visualized in Fig. 4, while a life-time occupational exposure (45 years) at the low-end exposure concentration of $0.05 \mathrm{mg} / \mathrm{m}^{3}$ is visualized in Fig. 5. The results confirm the build-up of alveolar retention, while the tracheobronchial region levels out to a larger degree. In the 1-year simulation with baseline input, the alveolar retention is found to exceed the tracheobronchial retention after approximately 250 days. At the end of 1 year, the tracheobronchial and alveolar retention was 1.15 and $2.85 \mu \mathrm{g} / \mathrm{cm}^{3}$, respectively, corresponding to a 11- and 34-fold increase from the 1-week exposure. After 45 years exposure to $0.05 \mathrm{mg} / \mathrm{m}^{3}$, the tracheobronchial and alveolar retention corresponded to 0.023 and $0.16 \mu \mathrm{g} / \mathrm{cm}^{2}$. 


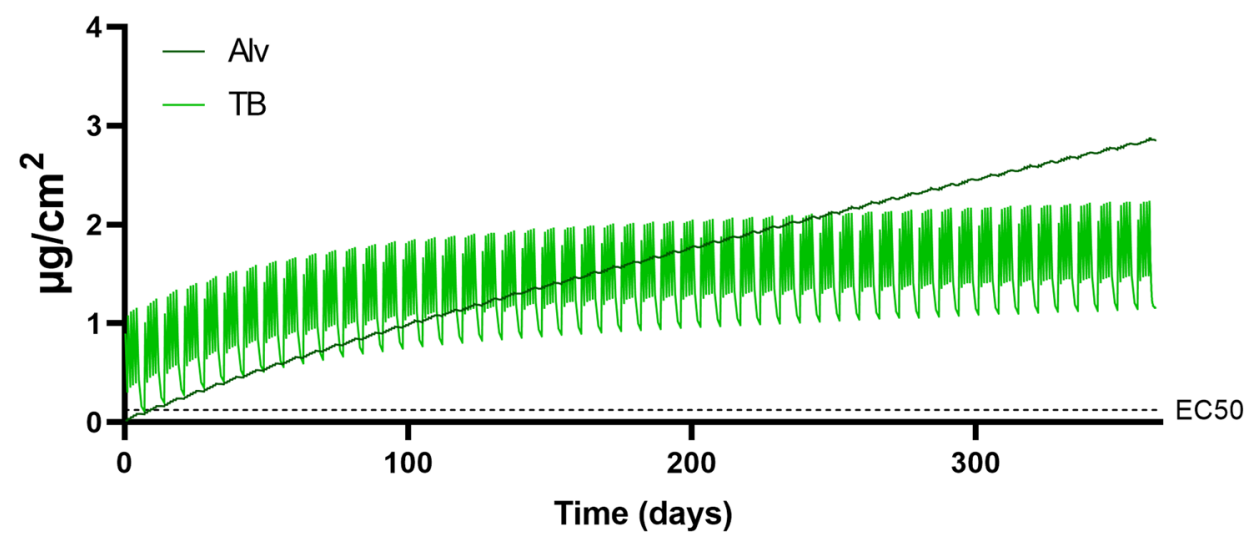

Fig. 4 MPPD model results of tracheobronchial or alveolar welding fume mass retained per surface area versus days of exposure up to 1 year. Baseline input values were used including the occupational exposure limit concentration of $5 \mathrm{mg} / \mathrm{m}^{3}$, a size distribution of CMD
$0.05 \mu \mathrm{m}$, GMD 1.2 and a moderate workload. The in vitro EC50 represents a responsive cell dose found to elicit a reduction of $50 \%$ cell viability in human bronchial epithelial cells following 24-h exposure

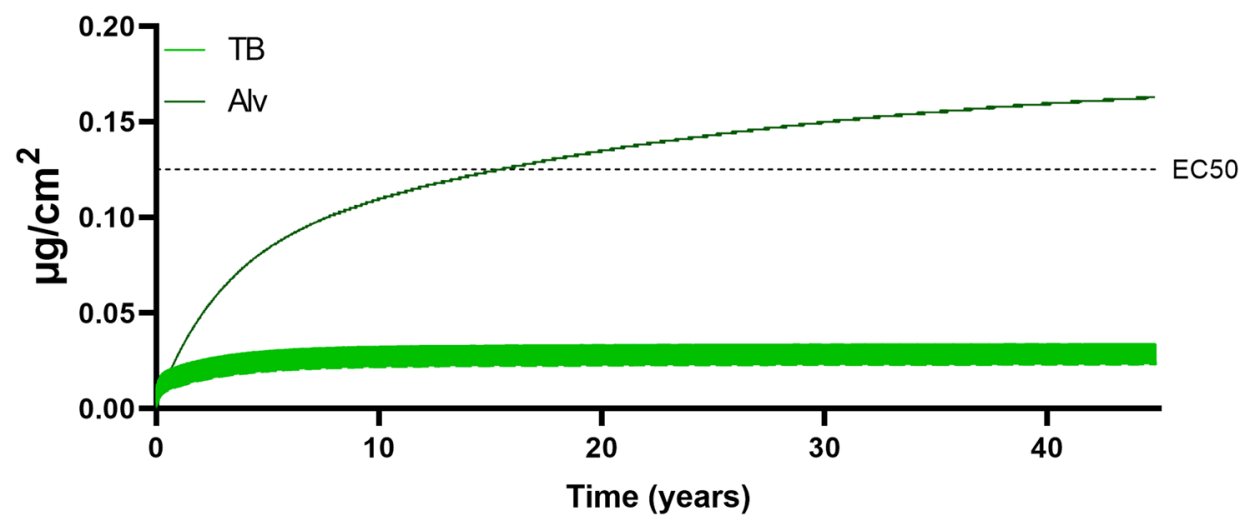

Fig. 5 MPPD model results of tracheobronchial or alveolar welding fume mass retained per surface area versus years of exposure up to 45 years. An occupational exposure of $0.05 \mathrm{mg} / \mathrm{m}^{3}$ was used with remaining baseline input values including a size distribution of CMD

\section{Comparison between modelled lung doses and those used in vitro}

To enable the comparison of real lung doses to those used in vitro, the estimated lung dose (retention) following the different exposure scenarios (altering concentrations and time of exposure) are compiled in Table 3, together with in vitro doses as extracted from McCarrick et al (2021) corresponding to $1.6-31.3 \mu \mathrm{g} / \mathrm{cm}^{2}$ when considering the nominal dose, or $0.08-1.57 \mu \mathrm{g} / \mathrm{cm}^{2}$ when considering cell dose (assuming 5\% uptake). One-year exposure to the OEL-level of $5 \mathrm{mg} / \mathrm{m}^{3}$ resulted in an alveolar retention exceeding the entire cell dose range tested in vitro.

The cytotoxic in vitro EC50 cell dose of $0.125 \mu \mathrm{g} / \mathrm{cm}^{2}$ was reached and exceeded in the tracheobronchial region
$0.05 \mu \mathrm{m}$, GSD 1.2 and a moderate workload. The in vitro EC50 represents a responsive cell dose found to elicit a reduction of $50 \%$ cell viability in human bronchial epithelial cells following 24-h exposure

following $6 \mathrm{~h}$ exposure to the OEL $5 \mathrm{mg} / \mathrm{m}^{3}$ (sevenfold). However, this was not the case at the end of 1 working week including weekend, i.e., 2 final days of only clearance and no exposure. The EC50 was further exceeded in both the tracheobronchial and alveolar region following 1 year of exposure to OEL $5 \mathrm{mg} / \mathrm{m}^{3}$ (9.2-fold and 23 -fold in tracheobronchial and alveolar region, respectively) or 1 week of exposure to the high-end concentration of $45 \mathrm{mg} / \mathrm{m}^{3}$ (seven and sixfold in tracheobronchial and alveolar region, respectively). In addition, an occupational lifetime exposure to the low-end concentration of $0.05 \mathrm{mg} /$ $\mathrm{m}^{3}$ resulted in alveolar retention comparable to the EC50 cell dose.

The EC50 was determined in bronchial epithelial cells, however we assume similar potency in alveolar cells. 
Table 3 Deposited welding fume particle dose for human inhalation exposure and in vitro exposure systems

\begin{tabular}{lllll}
\hline Exposure scenario & Exposure concentration & Exposure duration & Dose $\left(\mu \mathrm{g} / \mathrm{cm}^{2}\right)$ & \\
\hline Human inhalation & & & $\mathrm{TB}$ & Alv \\
OEL exposure & $5 \mathrm{mg} / \mathrm{m}^{3}$ & $6 \mathrm{~h}$ & 0.89 & 0.017 \\
& & 1 week & 0.102 & 0.083 \\
& & 1 year & 1.15 & 2.85 \\
Low end exposure & $0.05 \mathrm{mg} / \mathrm{m}^{3}$ & Lifetime $(45$ years $)$ & 0.023 & 0.16 \\
High end exposure & $45 \mathrm{mg} / \mathrm{m}^{3}$ & 1 week & 0.92 & 0.75 \\
In vitro (HBEC-3kt) & & & Nominal & Cell dose \\
Dose range & $5-100 \mu \mathrm{g} / \mathrm{mL}$ & $24 \mathrm{~h}$ & $1.6-31.3$ & $0.08-1.57$ \\
EC50 & $8 \mu \mathrm{g} / \mathrm{mL}$ & 2.5 & 0.125 \\
\hline
\end{tabular}

The modelled lung doses are presented in the tracheobronchial (TB) or alveolar (Alv) region. For the in vitro doses we assume $100 \mu \mathrm{L}$ of nanoparticle suspension is given into one well of a standard 96-well plate with a growth area of $0.32 \mathrm{~cm}^{2}$ per well assuming full sedimentation and bioavailability (nominal) or with a 5\% uptake (cell dose). The in vitro EC50 corresponds to the responsive cell dose of the most toxic welding fume found to elicit a reduction of $50 \%$ cell viability in human bronchial epithelial cells following 24-h exposure tested in McCarrick et al. (2021)

\section{Discussion}

The purpose of this study was to investigate the deposition of welding fume particles in the different regions of the lung to facilitate the translation between human exposure and in vitro concentrations to ultimately improve risk characterization. Using the MPPD model, we simulated various real-life occupational exposure scenarios to welding fumes under short- and long-term ( $6 \mathrm{~h}$ up to 45 years). Our results imply that the lung dose following these exposure scenarios to welding fumes are within the range of primarily low-end cell dose concentrations currently used in vitro. Nonetheless, our results further show that a 1-year occupational exposure to the OEL of $5 \mathrm{mg} / \mathrm{m}^{3}$ results in alveolar retention exceeding the cell dose following the highest concentration $(100 \mu \mathrm{g} / \mathrm{mL})$ tested in vitro. Interestingly, real-life occupational lung doses over both short and long-term exposure were found comparable to cell doses where toxic effects have been observed in vitro using human bronchial epithelial cells. Important to note though is that the in vitro effective dose is based on a bolus dose assessed at the acute timepoint of $24 \mathrm{~h}$, while corresponding lung doses are attained primarily following exposure over longer duration. However, the in vitro EC50 dose was found to be exceeded in the tracheobronchial region already after 1 working day (6-h exposure) at OEL aerosol concentration. The results demonstrate the potential of using real-life exposure data in combination with particle deposition modelling to improve the internal lung dose estimates. This will enhance the understanding of in vitro concentrations in the context of human occupational exposure and can be used as a tool in the study design of in vitro studies.

Our results emphasize the short-term concern for the tracheobronchial region but primarily the concern of alveolar retention for long-term occupational exposures to welding fume particles. The MPPD model predicts uniform deposition in each lung region meaning that all cells receive the same average dose. However, the deposition of particles in a human lung may be more heterogenous and contain hotspots, i.e., certain sites that may accumulate large fractions of the particles deposited. As an example, Ishikawa et al. (1994) demonstrated chromium concentrations to be higher at airway bifurcations than in neighboring epithelial tissue in exchromate workers. Based on this, our results are likely an underestimation of the tracheobronchial doses for cells located in certain areas, such as bifurcations. To further refine the deposition pattern derived from MPPD, complimentary models such as computational fluid dynamics models (CFD) should be considered to predict local deposition. By CFD modelling, Balashazy et al. (2003) demonstrated an enhancement of the deposition at tracheobronchial bifurcations to more than 100 times for micron-sized particles, and 5 to 60 -fold for nanosized particles as compared to the average values. Using this data, Phalen et al. (2006) further compared the tracheobronchial deposition by MPPD modelling with or without the addition of CFD-data for justification of in vitro doses, and demonstrated a 100 times difference in surface particle deposition. This suggest that if we would, as an example, include a safety factor of 100 for hotspots, the tracheobronchial retention following a lifetime exposure to low-end concentrations would increase from 0.023 to $2.3 \mu \mathrm{g} /$ $\mathrm{cm}^{2}$, and would thus exceed the entire range of cell doses tested in vitro. This would also alter the relationship between tracheobronchial and alveolar retention, where the tracheobronchial retention would exceed the alveolar retention in many cases.

The balance between deposition and clearance determines particle retention and lung burden. Default clearance settings of the MPPD model, as was used in this study, assume poorly soluble particles (Miller et al. 2016), whereas welding fume 
particles are expected to dissolve to varying extent (Antonini et al. 1999, 2005; McNeilly et al. 2004; Berlinger et al. 2019; McCarrick et al. 2019). The use of animal models could provide valuable mechanistic understanding of the fate of particles in an intact organism. Animal studies have demonstrated that various metals found in welding fumes are cleared from the lung at substantially different rates (Lam et al. 1978; Antonini et al. 2010, 2011). For example, whereas more than $80 \%$ of total deposited Mn had been cleared by 8 days and nearly all Mn by 21 days (in rats exposed to mild steel fume via inhalation), significant amounts (around 40\%) of Fe remained in the lungs at 42 days after exposure (Antonini et al. 2011). Based on this together with findings of an initial quick clearance face of $\mathrm{Fe}$, welding fume clearance has been suggested to be initially governed by mucociliary and lung macrophage clearance, followed by dissolution over time. The inclusion of welding-specific clearance and dissolution kinetics would reduce the residence time of the particles and thus the retention, especially in the long-term simulations. By including the kinetics of welding particle dissolution, this could also give valuable estimates of the internal lung dose of metal ions being released from welding fume particles. The MPPD model has previously been used to correlate lung deposition of silver nanoparticles to reported in vitro toxic threshold of ionic silver by assuming dissolution to a certain extent (Smith and Skinner 2021). The release of hexavalent chromium has for instance been suggested to be largely involved in welding particle toxicity by us (McCarrick et al. 2019, 2021) and others (Antonini et al. 1999, 2005; McNeilly et al. 2004), therefore this approach may be useful also for welding induced toxicity. To further refine dose estimates, MPPD models can also be combined with PBPK models, which has been carried out to derive target dose of manganese in human brain after inhalation of welding fumes (Ramoju et al. 2017).

The exposure concentration was found to be the most influential input parameter for lung retention of welding fume particles in our study, followed by workload and particle size distribution. The majority of the reported mass concentrations were below the OEL for inorganic inhalable dust of $5 \mathrm{mg} / \mathrm{m}^{3}$ but the levels varied to a large extent. The levels were, however, well in accordance with the welding fume concentrations reported by IARC ranging from $<1$ to $25 \mathrm{mg} / \mathrm{m}^{3}$ for stainless steel, and $<1$ to $>50 \mathrm{mg} / \mathrm{m}^{3}$ for mild steel (IARC 2017). This emphasizes the need to minimize exposure concentration, primarily with secondary protection such as proper ventilation and personal protection equipment. Factors in the concept of workload included breathing frequency and tidal volume, where an increased flow is expected to enhance deposition. Workload has been shown to vary among welders, where the majority were assessed as working under medium physical workload (Lehnert et al. 2015). Our results are in line with Gangwal et al. (2011), who also identified aerosol concentration and breathing patterns as primary key determinants in the prediction of alveolar retention of various metal-based nanoparticles in a sensitivity analysis using the MPPD model.

It is well established that particle size is a predictor of the site of deposition in the respiratory tract (Oberdörster et al. 2005; Hofmann 2020). The literature compiled suggest that welding fumes contain a high proportion of nanosized particles. However, the variation in reported size distribution is likely a reflection of altered factors such as welding process, wire feed rate and emission rate (Brand et al. 2012; Ennan et al. 2013). Our results confirmed the deposition of welding fume particles to be dependent on particle size distribution, which emphasizes the importance of well characterized welding fumes and the use of case-specific size distributions in deposition assessments. This can be exemplified by comparing results of our study with deposition fraction used by Falcone et al. (2017) in their human relevance deposition calculation. They used a deposition fraction of 0.16 for welding particles with a reported MMAD of $0.31 \mu \mathrm{m}$, whereas our baseline total deposition fraction was 0.43 for CMD of $0.05 \mu \mathrm{m}$. Moreover, the size of the particles may further influence lung retention in other ways than altering deposition. For example, particle size can impact clearance efficiency, where smaller nanoparticles have been suggested to escape phagocytosis to a greater extent compared to larger sized particles (Kreyling et al. 2006; Yang et al. 2008).

The in vitro doses used in the comparison were employed under submerged conditions for human bronchial epithelial cells (HBEC-3kt) (McCarrick et al. 2021). Other in vitro studies investigating welding fume toxicity have applied nominal doses varying between 2 and $250 \mu \mathrm{g} / \mathrm{mL}$ with a lowest dose generally ranging from 2 to $6.25 \mu \mathrm{g} / \mathrm{mL}$ (Antonini et al. 1999, 2005; McNeilly et al. 2004; Leonard et al. 2010; McCarrick et al. 2019; Hedberg et al. 2021). However, nominal media concentrations have been argued to be considered as measures of exposures rather than dose due to that they do not accurately reflect the dose in contact with the cells (Teeguarden et al. 2007; Groothuis et al. 2015). Therefore, the in vitro cellular dose, and not the nominal dose, was primarily considered in the comparison to the lung retention of welding fumes, demonstrating that response in human bronchial epithelial cells can be detected at cell doses attained following real-life exposure scenarios. The cellular dose was based on the $5 \%$ uptake as measured by ICP-MS in McCarrick et al. (2021), which can be considered as relatively low uptake. However, even if assuming 50\% uptake corresponding to a EC50 cell dose of $1.25 \mu \mathrm{g} / \mathrm{cm}^{2}$, this is still within a comparable magnitude as the modeled lung doses.

The in vitro EC50 was based on the most cytotoxic welding fume tested at $24 \mathrm{~h}$ and can therefore be considered somewhat a worst-case exposure, whereas other welding fume particles elicited a cytotoxic response first when high-end 
concentrations were used (McCarrick et al. 2021). In a recent study by Samulin Erdem et al. (2020), mild steel welding fumes were tested in vitro at low concentrations ranging between 0.035 and $4.375 \mu \mathrm{g} / \mathrm{mL}$ for $6 \mathrm{~h}$ per day during 5 consecutive days to more closely mimic occupational exposure patterns. However, the results demonstrated no cytotoxic effects on macrophages, epithelial or endothelial cells. Some studies have suggested that a higher threshold is required to elicit effects to occur in vitro compared to in vivo (animals). As an example, pro-inflammatory effects of poorly soluble nanomaterials were demonstrated to occur at lower alveolar surface doses in vivo compared to in vitro, where in vitro effects were observed at doses ten times higher at ALI or 20-100 times higher at submerged exposure (Loret et al. 2018). The higher concentrations required for in vitro response is pointing towards the higher complexity of in vivo models compared to the relatively simple in vitro models and could thus motivate the use of higher dose levels in vitro. Further research is however needed to find appropriate converting factors between in vitro and in vivo effects. More advanced cellular models including co-cultures or 3D-cultures as well as exposure under air-liquid interface (ALI) should also be considered in the future.

To our knowledge, this is the first study to model lung deposition of welding fume particles following simulations of real-life exposure scenarios and relate them to in vitro dose levels. As emphasized in Phalen et al. (2021), the experimental design of in vitro studies should be aiming at predicting effects in the target tissue of humans for specific use cases, including specific size distributions and ventilation rates relevant to the target population of interest, in which MPPD modelling offers this possibility. However, to facilitate the usage of dosimetry models, relevant and accurate exposure and particle characteristics data need to be available. In general, most studies investigating welding fume exposure did not measure or report size distribution, resulting in 64 out of the 79 articles identified being excluded due to insufficient size distribution data. To improve the deposition modelling of welding fumes, future studies should include measurements on both particle size and concentration. Another important aspect to highlight is the diversity in study design, measurement approaches and reporting of results of the different studies reviewed, probably a result of the miscellaneous aims of the studies. To obtain comparable and useful data for dosimetry modelling, harmonization of the measurement instruments and strategies would be beneficial.

\section{Conclusion}

The results reveal the concern of primarily tracheobronchial retention for short-term exposure to welding fumes, whereas alveolar retention is built up over time and thus of more concern for chronic exposure. Our results further suggest that lung doses retained following real-life occupational exposure scenarios of welders can be compared to cell doses found to elicit a toxic effect in vitro. The large deposition fraction in the tracheobronchial region results in retention exceeding the in vitro toxic dose already after one working shift at occupational exposure limit-level, although the retention is rapidly decreased after exposure stops. The regional lung deposition depends largely on aerosol concentration and time of exposure where the low-end exposure levels resulted in alveolar retention comparable to toxic in vitro doses first after 15-20 years and the tracheobronchial retention only if considering hotspots. The influence of parameters including aerosol concentration, size distribution and workload for lung retention was demonstrated, which emphasizes the importance in selection of input values specific to the target population. In all, this study demonstrates the potential of combining real-life exposure data with particle deposition modelling to improve lung dose estimates and provide a tool for dose selection in vitro. Understanding the association between occupational exposures and in vitro doses would improve study design as well as interpretation of toxicological results and hazard assessments.

Supplementary Information The online version contains supplementary material available at https://doi.org/10.1007/s00204-022-03247-9.

Acknowledgements This study was mainly supported by the Swedish Research Council for Environment, Agricultural Sciences and Spatial Planning (Formas, Grant 2017-00883). Funding from Swedish Governmental Agency for Innovation Systems (Vinnova Grant No. 201803336) is also acknowledged.

Author contributions Conceptualization: all authors, methodology: $\mathrm{SMc}, \mathrm{UC}$, formal analysis and investigation: SMc, UC, writingoriginal draft preparation: SMc, UC, writing - review and editing: all authors, funding acquisition: HLK, supervision: HLK, UC.

Funding Open access funding provided by Karolinska Institute.

\section{Declarations}

Conflict of interest The authors declare that they have no conflicts of interest.

Open Access This article is licensed under a Creative Commons Attribution 4.0 International License, which permits use, sharing, adaptation, distribution and reproduction in any medium or format, as long as you give appropriate credit to the original author(s) and the source, provide a link to the Creative Commons licence, and indicate if changes were made. The images or other third party material in this article are included in the article's Creative Commons licence, unless indicated otherwise in a credit line to the material. If material is not included in the article's Creative Commons licence and your intended use is not permitted by statutory regulation or exceeds the permitted use, you will need to obtain permission directly from the copyright holder. To view a copy of this licence, visit http://creativecommons.org/licenses/by/4.0/. 


\section{References}

Anjilvel S, Asgharian B (1995) A Multiple-path model of particle deposition in the rat lung. Fundam Appl Toxicol 28(1):41-50. https://doi.org/10.1006/faat.1995.1144

Antonini JM (2003) Health effects of welding. Crit Rev Toxicol 33(1):61-103. https://doi.org/10.1080/713611032

Antonini J, Lawryk N, Murthy GG, Brain JD (1999) Effect of welding fume solubility on lung macrophage viability and function in vitro. J Toxicol Environ Health A 58(6):343-363. https://doi. org/10.1080/009841099157205

Antonini JM, Leonard SS, Roberts JR, Solano-Lopez C, Young S-H, Shi X, Taylor MD (2005) Effect of stainless steel manual metal arc welding fume on free radical production, DNA damage, and apoptosis induction. Mol Cell Biochem 279(1):17-23. https:// doi.org/10.1007/s11010-005-8211-6

Antonini JM, Roberts JR, Chapman RS, Soukup JM, Ghio AJ, Sriram K (2010) Pulmonary toxicity and extrapulmonary tissue distribution of metals after repeated exposure to different welding fumes. Inhal Toxicol 22(10):805-816. https://doi.org/10.3109/ 08958371003621641

Antonini JM, Roberts JR, Stone S, Chen BT, Schwegler-Berry D, Chapman R, Zeidler-Erdely PC, Andrews RN, Frazer DG (2011) Persistence of deposited metals in the lungs after stainless steel and mild steel welding fume inhalation in rats. Arch Toxicol 85(5):487-498. https://doi.org/10.1007/s00204-010-0601-1

Asgharian B, Owen TP, Kuempel ED, Jarabek AM (2018) Dosimetry of inhaled elongate mineral particles in the respiratory tract: the impact of shape factor. Toxicol Appl Pharmacol 361:27-35. https://doi.org/10.1016/j.taap.2018.05.001

Balashazy I, Hofmann W, Heistracher T (2003) Local particle deposition patterns may play a key role in the development of lung cancer. J Appl Physiol (1985) 94(5):1719-1725

Berlinger B, Weinbruch S, Ellingsen DG, Zibarev E, Chashchin V, Chashchin M, Thomassen Y (2019) On the bio-accessibility of 14 elements in welding fumes. Environ Sci Process Impacts 21(3):497-505. https://doi.org/10.1039/C8EM00425K

Brand P, Lenz K, Reisgen U, Kraus T (2012) Number size distribution of fine and ultrafine fume particles from various welding processes. Ann Occup Hyg 57(3):305-313. https://doi.org/10. 1093/annhyg/mes070

Cena LG, Chen BT, Keane MJ (2016) Evolution of welding-fume aerosols with time and distance from the source: a study was conducted on the spatiotemporal variability in welding-fume concentrations for the characterization of first- and second-hand exposure to welding fumes. Weld J 95(Suppl):280s-285s

Debia M, Weichenthal S, Dufresne A (2014) Case study: ultrafine particles exposure in apprentice welders. J Occup Environ Hyg 11(1):D1-9. https://doi.org/10.1080/15459624.2013.836280

Ennan AA, Kiro SA, Oprya MV, Vishnyakov VI (2013) Particle size distribution of welding fume and its dependency on conditions of shielded metal arc welding. J Aerosol Sci 64:103-110. https://doi.org/10.1016/j.jaerosci.2013.06.006

Falcone L, Erdely A, Meighan T, Battelli LA, Salmen R, McKinney W, Stone S, Cumpston A, Cumpston J, Andrews RN, Kashon M, Antonini JM, Zeidler-Erdely P (2017) Inhalation of gas metal arc-stainless steel welding fume promotes lung tumorigenesis in A/J mice. Arch Toxicol 91(8):2953-2962. https://doi.org/10. 1007/s00204-016-1909-2

Gangwal S, Brown JS, Wang A, Houck KA, Dix DJ, Kavlock RJ, Hubal EAC (2011) Informing selection of nanomaterial concentrations for ToxCast in vitro testing based on occupational exposure potential. Environ Health Perspect 119(11):1539-1546. https://doi.org/10.1289/ehp.1103750
Graczyk H, Lewinski N, Zhao J, Concha-Lozano N, Riediker M (2016) Characterization of tungsten inert gas (TIG) welding fume generated by apprentice welders. Ann Occup Hyg 60(2):205-219. https://doi.org/10.1093/annhyg/mev074

Groothuis FA, Heringa MB, Nicol B, Hermens JL, Blaauboer BJ, Kramer NI (2015) Dose metric considerations in in vitro assays to improve quantitative in vitro-in vivo dose extrapolations. Toxicology 332:30-40. https://doi.org/10.1016/j.tox.2013.08. 012

Ham S, Yoon C, Lee E, Lee K, Park D, Chung E, Kim P, Lee B (2012) Task-based exposure assessment of nanoparticles in the workplace. J Nanopart Res 14(9):1126. https://doi.org/10.1007/ s11051-012-1126-8

Hedberg YS, Wei Z, McCarrick S, Romanovski V, Theodore J, Westin EM, Wagner R, Persson KA, Karlsson HL, Odnevall Wallinder I (2021) Welding fume nanoparticles from solid and flux-cored wires: Solubility, toxicity, and role of fluorides. J Hazard Mater 413:125273. https://doi.org/10.1016/j.jhazmat.2021.125273

Hedmer M, Karlsson JE, Andersson U, Jacobsson H, Nielsen J, Tinnerberg H (2014) Exposure to respirable dust and manganese and prevalence of airways symptoms, among Swedish mild steel welders in the manufacturing industry. Int Arch Occup Environ Health 87(6):623-634. https://doi.org/10.1007/s00420-013-0896-3

Hofmann W (2020) Regional Deposition: Deposition Models. J Aerosol Med Pulm Drug Deliv 33(5):239-248. https://doi.org/10.1089/ jamp.2020.29031.wh

IARC (2017) Welding, molybdenum trioxide and indium tin oxide. International Agency for Research on Cancer, Lyon

ICRP (1994) Human respiratory tract model for radiological protection. ICRP Publication 66. Ann. ICRP 24 (1-3)

Insley AL, Maskrey JR, Hallett LA, Reid RCD, Hynds ES, Winter C, Panko JM (2019) Occupational survey of airborne metal exposures to welders, metalworkers, and bystanders in small fabrication shops. J Occup Environ Hyg 16(6):410-421. https://doi.org/ 10.1080/15459624.2019.1603389

Ishikawa Y, Nakagawa K, Satoh Y, Kitagawa T, Sugano H, Hirano T, Tsuchiya E (1994) "Hot spots" of chromium accumulation at bifurcations of chromate workers bronchi. Cancer Res 54(9):2342

Kalliomäki PL, Alanko K, Korhonen O, Mattsson T, Vaaranen V, Koponen M (1978) Amount and distribution of welding fume lung contaminants among arc welders. Scand J Work Environ Health 4(2):122-130. https://doi.org/10.5271/sjweh.2715

Kirichenko KY, Vakhniuk IA, Rogulin RS, Kirichenko AV, Gridasov AV, Kosyanov DY, Drozd VA, Kholodov AS, Piekoszewski W, Golokhvast KS (2019) Characteristics of fume sedimentation in the working zone during arc welding with covered electrodes. Toxicol Environ Chem 101(9-10):463-474. https://doi.org/10. 1080/02772248.2020.1747465

Kreyling WG, Semmler-Behnke M, Möller W (2006) Ultrafine particlelung interactions: does size matter? J Aerosol Med 19(1):74-83. https://doi.org/10.1089/jam.2006.19.74

Lai C-Y, Lai C-H, Chuang H-C, Pan C-H, Yen C-C, Lin W-Y, Chen J-K, Lin L-Y, Chuang K-J (2016) Physicochemistry and cardiovascular toxicity of metal fume PM2.5: a study of human coronary artery endothelial cells and welding workers. Sci Rep 6(1):33515. https://doi.org/10.1038/srep33515

Lam HF, Hewitt PJ, Hicks R (1978) A study of pulmonary deposition, and the elimination of some metal constituent metals from welding fume in laboratory animals. Ann Occup Hyg 21(4):363-373. https://doi.org/10.1093/annhyg/21.4.363

Lehnert M, Pesch B, Lotz A, Pelzer J, Kendzia B, Gawrych K, Heinze E, Van Gelder R, Punkenburg E, Weiss T, Mattenklott M, Hahn JU, Möhlmann C, Berges M, Hartwig A, Brüning T (2012) Exposure to inhalable, respirable, and ultrafine particles in welding fume. Ann Occup Hyg 56(5):557-567. https://doi.org/10.1093/ annhyg/mes025 
Lehnert M, Hoffmeyer F, Gawrych K, Lotz A, Heinze E, Berresheim H, Merget R, Harth V, Van Gelder R, Hahn JU, Hartwig A, Weiß T, Pesch B, Brüning T (2015) Effects of exposure to welding fume on lung function: results from the German WELDOX study. Adv Exp Med Biol 834:1-13. https://doi.org/10.1007/5584_2014_65

Leonard SS, Chen BT, Stone SG, Schwegler-Berry D, Kenyon AJ, Frazer D, Antonini JM (2010) Comparison of stainless and mild steel welding fumes in generation of reactive oxygen species. Part Fibre Toxicol 7:32. https://doi.org/10.1186/1743-8977-7-32

Lin C-C, Chen M-R, Chang S-L, Liao W-H, Chen H-L (2015) Characterization of ambient particles size in workplace of manufacturing physical fitness equipments. Ind Health 53(1):78-84. https://doi. org/10.2486/indhealth.2014-0160

Loret T, Rogerieux F, Trouiller B, Braun A, Egles C, Lacroix G (2018) Predicting the in vivo pulmonary toxicity induced by acute exposure to poorly soluble nanomaterials by using advanced in vitro methods. Part Fibre Toxicol 15(1):25. https://doi.org/10.1186/ s12989-018-0260-6

McCarrick S, Wei Z, Moelijker N, Derr R, Persson KA, Hendriks G, Odnevall Wallinder I, Hedberg Y, Karlsson HL (2019) High variability in toxicity of welding fume nanoparticles from stainless steel in lung cells and reporter cell lines: the role of particle reactivity and solubility. Nanotoxicology 13(10):1293-1309. https:// doi.org/10.1080/17435390.2019.1650972

McCarrick S, Romanovski V, Wei Z, Westin EM, Persson KA, Trydell K, Wagner R, Odnevall I, Hedberg YS, Karlsson HL (2021) Genotoxicity and inflammatory potential of stainless steel welding fume particles: an in vitro study on standard vs $\mathrm{Cr}(\mathrm{VI})$-reduced flux-cored wires and the role of released metals. Arch Toxicol. https://doi.org/10.1007/s00204-021-03116-x

McNeilly JD, Heal MR, Beverland IJ, Howe A, Gibson MD, Hibbs LR, MacNee W, Donaldson K (2004) Soluble transition metals cause the pro-inflammatory effects of welding fumes in vitro. Toxicol Appl Pharmacol 196(1):95-107. https://doi.org/10.1016/j.taap. 2003.11.021

Miettinen M, Torvela T, Leskinen JT (2016) Physicochemical characterization of aerosol generated in the gas tungsten arc welding of stainless steel. Ann Occup Hyg 60(8):960-968. https://doi.org/ 10.1093/annhyg/mew039

Miller FJ, Asgharian B, Schroeter JD, Price O (2016) Improvements and additions to the multiple path particle dosimetry model. J Aerosol Sci 99:14-26. https://doi.org/10.1016/j.jaerosci.2016.01.018

Oberdörster G, Kuhlbusch TAJ (2018) In vivo effects: methodologies and biokinetics of inhaled nanomaterials. NanoImpact 10:38-60. https://doi.org/10.1016/j.impact.2017.10.007

Oberdörster G, Oberdörster E, Oberdörster J (2005) Nanotoxicology: an emerging discipline evolving from studies of ultrafine particles. Environ Health Perspect 113(7):823-839. https://doi.org/10.1289/ ehp.7339

Oller AR, Oberdörster G (2016) Incorporation of dosimetry in the derivation of reference concentrations for ambient or workplace air: a conceptual approach. J Aerosol Sci 99:40-45. https://doi.org/10. 1016/j.jaerosci.2016.01.015

Phalen RF, Oldham MJ, Nel AE (2006) Tracheobronchial particle dose considerations for in vitro toxicology studies. Toxicol Sci 92(1):126-132. https://doi.org/10.1093/toxsci/kfj182

Phalen RF, Hoover MD, Oldham MJ, Jarabek AM (2021) Inhaled aerosol dosimetry: research-related needs and recommendations. J Aerosol Sci 155:105755. https://doi.org/10.1016/j.jaerosci.2021. 105755

Ramoju SP, Mattison DR, Milton B, McGough D, Shilnikova N, Clewell HJ, Yoon M, Taylor MD, Krewski D, Andersen ME (2017) The application of PBPK models in estimating human brain tissue manganese concentrations. Neurotoxicology 58:226237. https://doi.org/10.1016/j.neuro.2016.12.001
Riccelli MG, Goldoni M, Poli D, Mozzoni P, Cavallo D, Corradi M (2020) Welding fumes, a risk factor for lung diseases. Int J Environ Res Public Health. https://doi.org/10.3390/ijerph17072552

Romeo D, Salieri B, Hischier R, Nowack B, Wick P (2020) An integrated pathway based on in vitro data for the human hazard assessment of nanomaterials. Environ Int 137:105505. https://doi.org/ 10.1016/j.envint.2020.105505

Sajedifar J, Kokabi AH, Dehghan SF, Mehri A, Azam K, Golbabaei F (2018) Evaluation of operational parameters role on the emission of fumes. Ind Health 56(3):198-206. https://doi.org/10.2486/ indhealth.2017-0155

Samulin Erdem J, Arnoldussen YJ, Tajik S, Ellingsen DG, Zienolddiny S (2020) Effects of mild steel welding fume particles on pulmonary epithelial inflammation and endothelial activation. Toxicol Ind Health 36(12):995-1001. https://doi.org/10.1177/0748233720 962685

Schmid O, Cassee FR (2017) On the pivotal role of dose for particle toxicology and risk assessment: exposure is a poor surrogate for delivered dose. Part Fibre Toxicol 14(1):52. https://doi.org/10. 1186/s12989-017-0233-1

Schmid O, Stoeger T (2016) Surface area is the biologically most effective dose metric for acute nanoparticle toxicity in the lung. J Aerosol Sci 99:133-143. https://doi.org/10.1016/j.jaerosci.2015.12.006

Shoeb M, Kodali V, Farris B, Bishop LM, Meighan T, Salmen R, Eye T, Roberts JR, Zeidler-Erdely P, Erdely A, Antonini JM (2017) Evaluation of the molecular mechanisms associated with cytotoxicity and inflammation after pulmonary exposure to different metal-rich welding particles. Nanotoxicology 11(6):725-736. https://doi.org/10.1080/17435390.2017.1349200

Sjögren B, Albin M, Broberg K, Gustavsson P, Tinnerberg H, Johanson G (2021) An occupational exposure limit for welding fumes is urgently needed. Scand J Work Environ Health. https://doi.org/ $10.5271 /$ sjweh. 4002

Smith JN, Skinner AW (2021) Translating nanoparticle dosimetry from conventional in vitro systems to occupational inhalation exposures. J Aerosol Sci 155:105771. https://doi.org/10.1016/j.jaero sci.2021.105771

Stanislawska M, Janasik B, Kuras R, Malachowska B, Halatek T, Wasowicz W (2020) Assessment of occupational exposure to stainless steel welding fumes-a human biomonitoring study. Toxicol Lett 329:47-55. https://doi.org/10.1016/j.toxlet.2020.04.019

Swedish Work Environment Authority (2018) Hygieniska gränsvärden (AFS 2018:1), föreskrifter. Swedish Work Environment Authority. https://www.av.se/arbetsmiljoarbete-och-inspektioner/publikatio ner/foreskrifter/hygieniska-gransvarden-afs-20181-foreskrifter/

Teeguarden JG, Hinderliter PM, Orr G, Thrall BD, Pounds JG (2007) Particokinetics in vitro: dosimetry considerations for in vitro nanoparticle toxicity assessments. Toxicol Sci 95(2):300-312. https:// doi.org/10.1093/toxsci/kfm097

Yang W, Peters JI, Williams RO (2008) Inhaled nanoparticles-a current review. Int J Pharm 356(1):239-247. https://doi.org/10. 1016/j.ijpharm.2008.02.011

Yang S-Y, Lin J-M, Young L-H, Chang C-W (2018) Mass-size distribution and concentration of metals from personal exposure to arc welding fume in pipeline construction: a case report. Ind Health 56(4):356-363. https://doi.org/10.2486/indhealth.2017-0197

Yeh H-C, Schum GM (1980) Models of human lung airways and their application to inhaled particle deposition. Bull Math Biol 42(3):461-480. https://doi.org/10.1016/S0092-8240(80)80060-7

Young L-H, Lin Y-H, Lin T-H, Tsai P-J, Wang Y-F, Hung S-M, Tsai C-J, Chen C-W (2013) Field application of a newly developed personal nanoparticle sampler to selected metalworking operations. Aerosol Air Qual Res 13(3):849-861. https://doi.org/10. 4209/aaqr.2012.10.0270

Zeidler-Erdely PC, Erdely A, Antonini JM (2012) Immunotoxicology of arc welding fume: worker and experimental animal studies. J 
Immunotoxicol 9(4):411-425. https://doi.org/10.3109/1547691X. 2011.652783

Zugasti A, Montes N, Rojo JM, Quintana MJ (2012) Field comparison of three inhalable samplers (IOM, PGP-GSP 3.5 and button) for welding fumes. J Environ Monit 14(2):375-382. https://doi.org/ 10.1039/C1EM10616C
Publisher's Note Springer Nature remains neutral with regard to jurisdictional claims in published maps and institutional affiliations. 